\title{
FACEBOOK COMO FERRAMENTA PEDAGÓGICA NOS CURSOS DE SEGUNDA LICENCIATURA E FORMAÇÃO PEDAGÓGICA NA MODALIDADE EAD: UM RELATO DE EXPERIÊNCIA DE PROFESSORES- TUTORES
}

\author{
CURITIBA/PR MAIO/2018
}

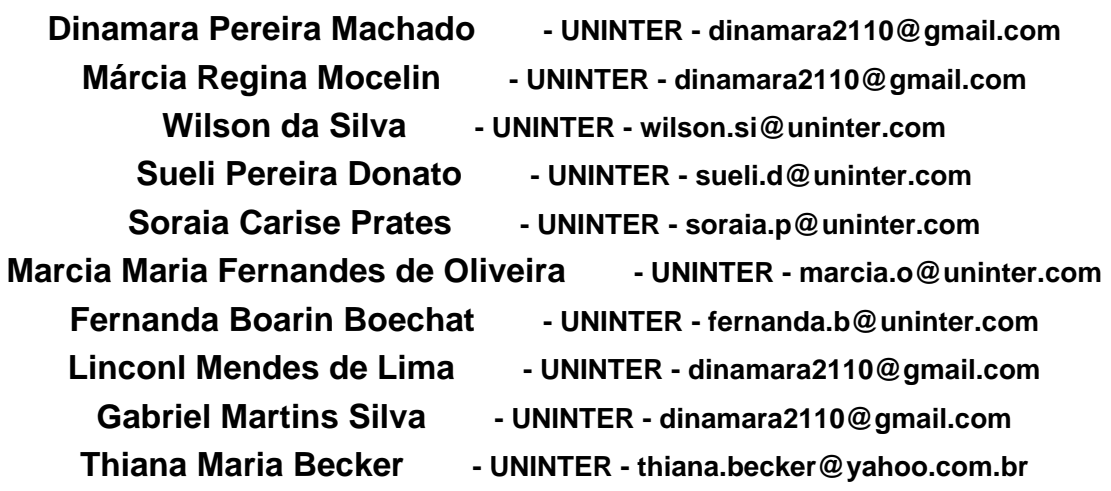

Tipo: Relato de Experiência Inovadora (EI)

Categoria: Métodos e Tecnologias

Setor Educacional: EDUCAÇÃO SUPERIOR

\begin{abstract}
RESUMO
Este artigo trata do uso do Facebook como ferramenta pedagógica nos cursos de Segunda Licenciatura (SL) e Formação Pedagógica (FP) na modalidade EaD através do relato de experiências de professores tutores de uma instituição de ensino superior particular. O objetivo é demonstrar que assim como existem novos meios de comunicação, também há novas formas de aprendizagem. Justifica-se esta pesquisa pelo fato dos cursos de SL e FP utilizarem a ferramenta Facebook - Live para mediarem conteúdos, reforçando o ensino aprendizagem dos alunos. A metodologia utilizada foi o relato de experiência dos(as) professores(as) tutores dos cursos de SL e FP da instituição pesquisada, entrelaçado a fundamentação teórica guiada pelos autores principais Amante (2005), Patricio e Gonçalves (2007), Machado e Machado (2004) apoiada em Palloff e Pratt (2002), Machado (2016) e Morin (2018). O uso do Facebook - live se dá na modalidade de educação a distância como ferramenta alternativa e complementar no processo de ensino e aprendizagem, oportunizando aos educandos outras possibilidades de mediação na aprendizagem. Assim, para além da sala de tutoria, contemplase diferentes estilos de aprendizagem por parte de nossos estudantes. Mediante essas ponderações, depreendemos que o uso do Facebook - live, como ferramenta pedagógica alternativa e complementar ao trabalho da tutoria online, tem privilegiado um espaço de reflexão coletiva entre professores-tutores, participativa e, por consequência, uma aprendizagem mais significativa aos nossos estudantes, que encontram nessa ferramenta a oportunidade de interação e protagonismo de sua aprendizagem.
\end{abstract}

Palavras-chave: Professores-tutores. Facebook. Aprendizagem. Segunda Licenciatura. Formação Pedagógica.Tecnologias. 


\section{FACEBOOK COMO FERRAMENTA PEDAGÓGICA NOS CURSOS DE SEGUNDA LICENCIATURA E FORMAÇÃO PEDAGÓGICA NA MODALIDADE EaD: UM RELATO DE EXPERIÊNCIA DE PROFESSORES-TUTORES}

\section{INTRODUÇÃO}

No século XXI, a presença da internet ganha cada vez mais espaços em nossas vidas, a exemplo de blogs, podcasts, wikis, redes sociais, plataformas que viabilizam a interação do sujeito com o mundo em tempo real e, por consequência, oportunizam novos modos de comunicação, pesquisas, aprendizagem, entre outros. Segundo o Ministério da Educação, a Educação a Distância é a modalidade educacional na qual a mediação didático-pedagógica nos processos de ensino e aprendizagem ocorre com a utilização de meios e tecnologias de informação e comunicação, com estudantes e professores desenvolvendo atividades educativas em lugares ou tempos diversos. Esta definição está presente no Decreto 5.622, de 19.12.2005 (que revoga o Decreto 2.494/98), que regulamenta o Art. 80 da Lei 9.394/96 (LDB). (BRASIL, 2018) . Na definição de Belloni (2002, p. 123) a EaD é vista "[...] como parte de um processo de inovação educacional mais amplo, que é a integração das novas tecnologias de informação e comunicação nos processos educacionais".

Desse cenário, vislumbra-se a potencialidade das redes sociais na educação, de forma a contribuir com o processo de ensino e aprendizagem dos estudantes na modalidade de Educação a Distância. Dentre elas, ganha relevo neste relato teórico-prático, a rede social Facebook, criada em fevereiro de 2004 por Mark Zuckerberg, ex-estudante da Universidade de Harvard. Neste viés, destaca-se, na condição de professores-tutores de cursos de Segunda Licenciatura (SL) e Formação Pedagógica (FP), que o uso da rede social - aqui mais especificamente a ferramenta Live do Facebook - pode auxiliar a comunicação com os estudantes que fazem uso do link tutoria no ambiente virtual de aprendizagem (AVA) ao postar suas dúvidas de conteúdo. Tal comunicação objetiva proporcionar uma tutoria proativa e, por consequência, ampliar as possibilidades de aprendizagem mais colaborativa e significativa nesta modalidade e ensino.

Assim, a partir da experiência dos professores-tutores (todos doutores) nos últimos seis meses na tutoria online de cursos de Segunda Licenciatura e Formação Pedagógica na modalidade de Educação a Distância, definiu-se utilizar o recurso Facebook - live como alternativa para discutir dificuldades dos alunos mencionadas nas salas de tutoria dos referidos cursos de uma instituição particular de ensino superior do município de Curitiba/PR. Por fim, o texto que segue está estruturado em um diálogo entre a experiência referida e autores que discutem o uso de redes sociais na educação, em 
especial o uso do Facebook no contexto da Educação a Distância. Alguns apontamentos sobre a tutoria online e procedimentos metodológicos serão ainda feitos aqui, seguidos de considerações finais sobre a experiência apresentada.

\section{REDES SOCIAIS E A EDUCAÇÃO: O FACEBOOK COMO PLATAFORMA DE COMUNICAÇÃO}

Michel Serres na obra Polegarzinha, publicado em 2013, aponta para a comparação entre as maneiras de utilização do conhecimento entre os alunos do período analógico e os alunos conectados via web. O autor salienta que seus alunos mais antigos faziam as anotações em notas de pé de página e em densas bibliografias de livros, enquanto atualmente os alunos, os envia e-mails. As tecnologias provindas da internet podem se tornar ferramentas de ensino de professores, que delineiam estratégias pedagógicas conforme objetivos definidos, de modo a flexibilizar os contextos de aprendizagem, individuais e coletivos, proporcionando que os alunos construam, interajam e partilhem o seu próprio conhecimento.

Dentre as redes sociais existentes, parece ser o Facebook uma das redes sociais mais utilizadas com o objetivo de interação social. Criado em 2004 - conforme Amante (Amante apud Arrington, 2005), por um grupo de jovens universitários de Harvard (Mark Zuckerberg, Dustin Moskovitz, Eduardo Saverin e Chris Hughes) - a plataforma visava criar um espaço no qual as pessoas se encontrassem, compartilhassem opiniões e fotografias. A princípio, o objetivo era criar uma rede de comunicação apenas para os estudantes da própria Universidade. Todavia, em poucos meses a rede expandiu-se entre as universidades norte-americanas, conectando jovens de mais de 800 instituições. A sua popularidade cresceu e, em menos de um ano já tinha 1 milhão de utilizadores ativos. A partir de 2005, o uso do Facebook ultrapassa o território norteamericano e, em 2006, o Facebook foi aberto ao público geral, restringindo o uso somente a menores de treze anos. No final do ano de 2011, no Brasil, o Facebook ultrapassou o Orkut, que era já naquela época a maior rede social do país.

Segundo Patrício e Gonçalves (Patrício e Gonçalves apud Kelly, 2007) o Facebook transformou-se não só em um canal de comunicação e um destino para pessoas interessadas em procurar, partilhar ou aprender sobre determinado assunto, mas igualmente passa a ser um meio de oportunidades no âmbito do ensino superior. Particularmente, trata-se de uma ferramenta popular, fácil de usar e não necessita de desenvolvimento interno ou de aquisição de software. Assim ela é útil para alunos, professores e funcionários e permite a integração de diversos recursos no Facebook (RSS feeds, blogs, twitter etc.). Além do mencionado, o Facebook fornece alternativas 
de acesso a diferentes serviços, permite o controle de privacidade (podemos controlar a informação que queremos que os outros vejam sobre nós). Por fim, não é possível, também no contexto brasileiro, ignorar tal ferramenta.

\section{TUTORIA ON-LINE NO CONTEXTO DA EDUCAÇÃO A DISTÂNCIA: ALGUNS APONTAMENTOS}

Pensar a tutoria online na contemporaneidade implica em refletirmos sobre o papel do professor-tutor neste cenário, que requer, cada vez mais, um professor-tutor engajado com o processo de ensino e aprendizagem. Sobre isto, Machado e Machado (2004) apoiada em Palloff e Pratt (2002) contribuem ao apresentar uma classificação de tarefas e papéis do professor online em quatro áreas: pedagógica, gerencial, técnica e social (Quadro 1):

Quadro 1 - Classificação de tarefas e papéis do professor online

\begin{tabular}{|l|l|}
\hline Função & $\begin{array}{l}\text { Diz respeito ao fomento de um ambiente social amigável, essencial à } \\
\text { pedagógica }\end{array}$ \\
aducacional é o de garantir que o processo educativo ocorra entre os \\
alunos. No ambiente online, o professor torna-se um facilitador. Ele \\
conduz o grupo de maneira mais livre, permitindo aos alunos explorar o \\
material do curso, ou a ele relacionados, sem restrição. O docente pode \\
trazer assuntos gerais para serem lidos e comentados, além de fazer \\
perguntas visando a estimular o pensamento crítico sobre o assunto \\
discutido. É importante que o professor comente adequadamente as \\
mensagens dos alunos, as quais servirão para estimular debates \\
posteriores. (Nesse contexto, o professor atua como animador, tentando \\
motivar seus alunos a explorarem o material mais profundamente do que \\
fariam na sala de aula presencial.)
\end{tabular}




\begin{tabular}{|l|l|}
\hline Função social & $\begin{array}{l}\text { grande importância. Todos precisamos estar cônscios do impacto que a } \\
\text { EaD online tem na aprendizagem e facilitar a mudança de paradigma } \\
\text { necessária ao aluno para que ele tenha maior impacto. }\end{array}$ \\
\hline $\begin{array}{l}\text { Significa facilitação educacional. O professor é responsável por facilitar e } \\
\text { dar espaço aos aspectos pessoais e sociais da comunidade online. Collins } \\
\text { Berge (1996, apud Palloff; Pratt, 2002:104), referem-se a essa função } \\
\text { como "estímulo às relações humanas, com a afirmação e o } \\
\text { reconhecimento da contribuição dos alunos; isso inclui manter o grupo } \\
\text { unido, ajudar de diferentes formas os participantes a trabalharem juntos } \\
\text { por uma causa comum e oferecer aos alunos a possibilidade de } \\
\text { desenvolver sua compreensão da coesão do grupo". }\end{array}$ \\
\hline
\end{tabular}

Fonte: Adaptado de Machado e Machado (2004) apoiados em Palloff e Pratt (2002).

Os Referenciais de Qualidade para Educação Superior a Distância do Ministério da Educação - MEC (BRASIL, 2007) norteiam a elaboração de propostas para cursos e sistemas de Educação a Distância, trazendo as seguintes informações para o tutor, tanto presencial quanto à distância:

[...] em qualquer situação, ressalta-se que o domínio do conteúdo é imprescindível, tanto para o tutor presencial quanto para o tutor a distância e permanece como condição essencial para o exercício das funções. Esta condição fundamental deve estar aliada à necessidade de dinamismo, visão crítica e global, capacidade para estimular a busca de conhecimento e habilidade com as novas tecnologias de comunicação e informação. (BRASIL, 2007, p. 22).

Depreendemos que mediar o processo ensino e aprendizagem, mesmo em um ambiente como a EaD, exige rigorosidade metódica, já que o educador que se diz: [...] democrático, crítico, em sua prática docente deve forçar a capacidade de crítica do educando, sua curiosidade, sua insubmissão. Trabalhar com os educandos a rigorosidade metódica com que devem se "aproximar" dos objetos cognoscíveis, é uma de suas tarefas primordiais. (FREIRE, 1996, p.32). Compreendemos que qualquer coisa contrária a esse posicionamento "[...] é amesquinhar o que há de fundamentalmente humano no exercício educativo: o seu caráter formador" (FREIRE, 1996, p.33). Assim, prosseguimos tomando a vivência da prática docente dos professores-tutores de uma 
instituição do ensino superior de grande porte da rede privada de ensino de Curitiba/PR como referencial, respaldada na abordagem qualitativa de pesquisa, opção metodológica para subsidiar tal estudo.

\section{A VIVÊNCIA DO USO DO FACEBOOK- LIVE ALIADA À TUTORIA ONLINE NOS CURSOS DE SEGUNDA LICENCIATURA E FORMAÇÃO PEDAGÓGICA NA EaD: OLHARES DE SI}

A busca pela excelência da/na tutoria online no contexto da presente instituição lócus do presente relato no sentido de assegurar uma tutoria proativa - constitui-se em um aspecto inegociável no projeto político pedagógico do curso (PPC). Tal concepção, se respalda nos argumentos de Machado (2016) a partir de documentos institucionais ao enfatizar a necessidade de uma concepção proativa de tutora online em que os professores tutores ultrapassem a recepção de dúvidas pedagógicas dos acadêmicos e estabeleçam mecanismos antecipando os pontos nevrálgicos de entendimento conceitual.

A tutoria proativa constitui-se como prática formativa amparada no desenvolvimento de conhecimento, habilidades, atitudes, valores e emoção. Assim, as tecnologias assumem papel de meio no processo educacional, e professor e aluno ocupam o processo de aprendizagem. $O$ aluno como protagonista e o professor tutor como mediador. $O$ professor como mediador interliga e provoca situações de aprendizagem, utilizando diversos canais de comunicação, de roteiros que conduzem para pesquisa, de atividade práticas a partir de estudo de caso, e de debates entre alunos de diferentes regiões do país. A tutoria proativa evidencia-se também com atendimento personalizado, que é possível ser realizado em EAD, a partir da análise dos resultados obtidos pelos alunos no processo de avaliação. Dessa forma, delineia-se um agir pedagógico para atender os pontos que não foram absorvidos pelos acadêmicos em seu processo educacional.

Compreender que para realização da tutoria proativa existe uma mudança de ruptura do trabalho do professor. Ele deixa de ser passivo diante do aluno apenas expondo conteúdos e trabalha a partir da provocação conceitual com os alunos, percebe, então, falácias no desenvolvimento da aprendizagem. A mudança de professor-tutor para professor-tutor com postura proativa requer ser mediador entre conhecimento e aluno, e este perfil favorece o desenvolvimento de novas metodologias no trabalho docente.

A instituição prevê em seu PPC, bem como na prática, a efetivação de uma tutoria proativa em todos os cursos de Licenciaturas, que neste relato, é priorizado a vivência no âmbito dos cursos de Segunda Licenciaturas e Formação Pedagógica. Nesse 
sentido, há uma perspectiva de que ao efetivar tal postura os professores-tutores se colocam na condição de mediadores da aprendizagem dos estudantes, para além, de práticas de caráter meramente técnicos. Sob essa perspectiva, vivenciamos uma constante preocupação e reflexão na e sobre a ação, pela proposta de tutoria online que a referida instituição sustenta.

A tutoria online da instituição pesquisada tem por objetivo a aprendizagem e a comunicação bidirecional entre os atores educacionais. A ressignificação e a troca interativa entre os sujeitos da aprendizagem estão baseadas na construção e reconstrução do conhecimento por meio de rotas de aprendizagem, vídeos, da participação em redes sociais e interação dos polos de apoio. Vale mencionar que para a instituição pesquisada, alguns princípios são elementares. São eles a autonomia, a singularidade, a interatividade e a acessibilidade.

A autonomia é o que queremos propiciar ao aluno, compreendendo-o como um indivíduo que realiza novas ações a partir dos conteúdos e da interação com outros participantes do processo. Espera-se que esse aluno investigue novas formas, que descubra a formação continuada, que aprenda por si mesmo e ajude na transformação da realidade social. O aluno deve participar ativamente das atividades do curso, sendo protagonista na construção do conhecimento. A singularidade se deve ao respeito ao aluno, ao reconhecimento dos estudos e pesquisas que resultaram da corrente epistemológica da Andragogia e à possibilidade de se propiciar uma multiplicidade de práticas pedagógicas com as quais cada indivíduo possa pertencer a uma comunidade de prática nas redes sociais e a uma experiência social de aprendizagem no encontro presencial.

O termo interatividade refere-se à utilização de aparatos tecnológicos para a comunicação entre um ou mais indivíduos, seja ela síncrona ou assíncrona. É a interação online. Os alunos devem trabalhar colaborativamente em uma perspectiva proativa, interagindo uns com os outros na realização das atividades do curso, como por exemplo, os fóruns e lives (do Facebook).

A acessibilidade diz respeito à inserção de todos os atores educacionais, à agilidade nos processos tecnológicos e à naturalização do uso de ferramentas. Para atender aos princípios acima mencionados, entendemos que a atividade do professor-tutor (online) é um mecanismo que ajuda na construção do processo de aprendizagem do aluno adulto. Entendemos que as tecnologias digitais são meios agregadores no trabalho educacional e no desenvolvimento do ser humano. Assim, potencializamos o uso de ferramentas de colaboração e interação (fórum, aulas interativas, lives, entre outros). 
Ao longo do curso, o aluno deve realizar as atividades avaliativas, tanto no próprio ambiente virtual como também na instituição (polo de apoio), participar de atividades de grupo, como os Estudos de Caso (fórum) e do Portfólio. Há também ferramentas para envio de trabalhos e/ou materiais em diferentes formatos de arquivos (doc, pdf, xls, wmv, jpg etc.), que possibilitam o desenvolvimento de atividades individuais, objetivas ou dissertativas, além de ferramentas colaborativas. Isso tudo para que seu processo de aprendizagem aconteça de forma cumulativa e formativa a partir de questionamentos e problematizações.

Tais atividades estão em total consonância com o princípio do action learning, que consiste em um modelo de aprendizagem empírica resultante das experiências vivenciadas pelos agentes do processo educativo envolvidos em atividades contextualizadas e problematizadoras. Percebe-se, nesse processo, a compreensão sistêmica do conteúdo e a potencialização da construção do conhecimento individual a partir de dinâmicas de vivências em grupo, compartilhadas em rede virtual ou presencial. Essas atividades são elaboradas a partir de princípios andragógicos que buscam atender $o$ aluno adulto.

O professor-tutor recebe e responde as dúvidas sobre conteúdo e atividades por meio de mensagens pelo AVA e debate (fórum), além de direcionar os alunos nas pesquisas a serem realizadas para estudos complementares que o aluno desejar. Os alunos também podem interagir com o coordenador do curso, pois o mesmo atende pelo ambiente virtual de aprendizagem e acompanha as interações entre todos os envolvidos, bem como interage com os alunos conforme a necessidade via e-mail. Para atender aos preceitos de aprendizagem do adulto e dos novos recursos das tecnologias digitais da informação e comunicação, a instituição pesquisada possui um quadro de profissionais oriundos de várias áreas do saber, que realizam funções distintas, de forma ordenada a partir de uma metodologia focada em potencializar materiais e espaços para o desenvolvimento da interação.

Entendemos que o diferencial desta concepção de tutoria em uma perspectiva proativa que alia ferramentas pedagógicas inovadoras, como Facebook - live, para potencializar e dinamizar o feedback aos nossos estudantes no que se refere às dúvidas de conteúdos postadas diariamente, rompe com o papel de um professor-tutor meramente técnico. Esse professor-tutor não é mais mero transmissor de informações, à medida que assume o papel de mediador do conhecimento, orientador do processo de aprendizagem. Desse modo, apesar de separados espacial e/ou temporalmente, eles assumem a desejada condição proativa no contexto da tutoria online e rompem com paradigmas tradicionais, haja vista, que no contexto do século XXI "[...] o professor 
como orientador ou mentor ganha relevância. O seu papel é ajudar os alunos a irem além de onde conseguiriam ir sozinhos, motivando, questionando, orientando" (MORAN, 2018, p. 29). Tais características e posicionamentos revelam uma concepção de que formar está longe de transformar a experiência educativa em puro treinamento técnico como alerta Freire (1996).

\section{CONSIDERAÇÕES FINAIS}

A partir do exposto no presente texto, consideramos que a postura do professor-tutor esperado pela instituição de ensino pesquisada, assim como o formato que se propõe $o$ processo de ensino-aprendizagem na modalidade EaD vão ao encontro da proposta de uso do Facebook-live como ferramenta de aprendizagem no referido contexto. Nesse sentido, alia-se uma ferramenta tecnológica - aqui o Facebook -, quase sempre já usado pelo aluno no contexto social comum, ao processo de ensino e aprendizagem como facilitador desse mesmo processo. Os professores-tutores, portanto, a partir dessa postura proativa, identificam através dos diferentes mecanismos já disponibilizados pela plataforma virtual da instituição (AVA) as eventuais dificuldades ou dúvidas dos mesmos. Depois disso, através do recurso disponível pelo Facebook, a live, já conhecido do aluno usuário de rede social, a equipe pedagógica discute as dificuldades identificadas, potencializando, portanto, as possibilidades de interação do aluno no processo de ensino e aprendizagem. Partindo dessas reflexões, consideramos relevante e oportuna a reflexão tecida ao longo deste texto a partir de constatações de professores-tutores dessa instituição de ensino superior, interessados em aperfeiçoar mecanismos que potencializem o processo de aprendizagem, aproximando o aluno do mesmo e lhe proporcionando um maior protagonismo.

\section{REFERÊNCIAS}

AMANTE, L. Disponível em: $<$ http://portal.mec.gov.br/instituicoes-credenciadas/educacao-superior-a-distancial $>$. Acesso em: 10 maio 2018.

BELLONI, M. L. Ensaio sobre a educação a distância no Brasil. Revista Educação \& Sociedade. Campinas: Unicamp, v. 23, n. 78, p. 117-142, abr./2002.

BRASIL. Ministério da Educação. Secretaria de Educação a Distância - MEC. Referenciais de Qualidade para a Educação Superior a Distância. 2007. Disponível em:<http://portal.mec.gov.br/seed/arquivos/pdf/legislacao/refead1.pdf>. Acesso em: 23 fev. 2018. 
BRASIL. Decreto n. 9.057 de 25 de maio 2017. Regulamenta o art. 80 da Lei no 9.394, de 20 de dezembro de 1996, que estabelece as diretrizes e bases da educação nacional. Diário Oficial da União, Brasília, DF, 25 maio.2017. Disponível em: <http://www.planalto.gov.br/ccivil_03/_ato2015-2018/2017/decreto/D9057.html>.Acesso em: jan. 2018.

BRASIL. Decreto n. 5.622, de 19 de dezembro de 2005. Regulamenta o art. 80 da Lei n. 9.394, de 20 de dezembro de 1996, que estabelece as diretrizes e bases da educação nacional. Diário Oficial da União, Brasília, DF, 20 dez. 2005. Disponível em: <http://www.planalto.gov.br/ccivil_03/_Ato2004-2006/2005/Decreto/D5622.htm>.Acesso em: 05 jan. 2018.

BRASIL. Lei n. 9.394, de 20 de dezembro de 1996. Estabelece as diretrizes e bases da educação nacional. Diário oficial da União. Brasília, DF, 23 dez. 1996. Disponível em: < http://www.planalto.gov.br/ccivil_03/leis/19394.htm >. Acesso em: 05 jan. 2018.

FREIRE, Paulo. Pedagogia da autonomia: saberes necessários à prática educativa. São Paulo: Paz e Terra, 1996.

MACHADO, L. D.; MACHADO, E. C. O Papel da tutoria em ambientes EaD. ABED. 2004. Disponível em: < http://www.abed.org.br/congresso2004/por/htm/022-tc-a2.htm>. Acesso em: 20 abr.2018.

MORAN, José. Metodologias ativas para uma aprendizagem mais profunda. In: $\mathrm{BACICH}$, Lilian. MORAN, José (Orgs.). Metodologias ativas para uma educação inovadora: uma abordagem teórico-prática [recurso eletrônico]. Porto Alegre: Penso, 2018. e-PUB.

PALLOFF, Rena; PRATT, Keith. Construindo Comunidades de Aprendizagem no Ciberespaço. Porto Alegre, Artmed, 2002.

PORTO, Cristiane; SANTOS, Edmea (Orgs.). Facebook e educação: publicar, curtir, compartilhar. Campina Grande: EDUEPB, 2014.

PATRÍCIO, R; GONÇALVES, V. Facebook: rede social educativa? Disponível em: <https://bibliotecadigital.ipb.pt/bitstream/10198/3584/1/118.pdf>. Acesso em: 10 maio 2018. 